\title{
PERCEPÇÕES SOBRE ADOECIMENTO PARA CAMINHONEIROS AFASTADOS PELO SISTEMA DE PREVIDÊNCIA SOCIAL
}

\author{
Lívia Guimarães Delfino \\ Instituto Nacional de Seguridade Social/Espírito Santo
}

Thiago Drumond Moraes

Universidade Federal do Espírito Santo

\begin{abstract}
Resumo
Objetiva-se compreender o afastamento do trabalho de caminhoneiros de rota longa em benefício previdenciário e com indicação de reabilitação profissional pelo Instituto Nacional do Seguro Social (INSS) visando conhecer como percebiam seu trabalho e os fatores ligados a seu processo de adoecimento. Em pesquisa de abordagem qualitativa, entrevistou-se individualmente 13 caminhoneiros, homens, com idades entre 30 e 58 anos. Dos relatos identificaram-se categorias como características e condições do trabalho, expectativas e ganhos profissionais e adiamento do cuidado. Os dados demonstram percepção do afastamento por doenças relacionado à atual organização do transporte rodoviário de cargas e que esse afastamento tem ocorrido tardiamente com o agravamento das morbidades, ficando evidente a influência dos modos de lidar com o adoecer destes trabalhadores. O estudo demonstra necessidade de aprimoramento constante das ações da Previdência Social principalmente no que se refere às especificidades de determinados grupos profissionais no serviço de reabilitação profissional do INSS.
\end{abstract}

Palavras-chave: seguridade social; saúde ocupacional; aposentadoria; condições de trabalho; transportes.

\section{ILNESS' PERCEPTION FOR TRUCK DRIVERS ABSENTED BY SOCIAL SECURITY SYSTEM}

\begin{abstract}
This article aims to comprehend the configuration of the absence from work for long distance truck drivers in pension benefit and indication of vocational rehabilitation by the National Social Security Institute (INSS) seeking their work's perception and factors related to the disease process. In qualitative research aproach, thirteen males truck drivers, between 30 and 58 years, were individually interviewed in a semistructured interview. In the reports were identified categories like work characteristics and conditions, professional expectations and gains and postponement of care. This data revealed perception that the absence from work is related to current organization of road transport loads; and that the sick leave have occurring later with worsening morbidities, evidencing the influence coping with the illness in the process. The research pointed the need for constant improvement of the shares of Social Security mainly with regard to the specificities of certain professional groups in the INSS rehabilitation service.
\end{abstract}

Keywords: social welfare; occupational health; retirement; working conditions; transportation. 


\title{
PERCEPCIONES SOBRE ENFERMEDAD PARA CAMIONEROS AUSENTADOS POR LO SISTEMA DE SEGURIDAD SOCIAL
}

\begin{abstract}
Resumen
Objetiva-se describir la configuración del abandono del trabajo para camioneros de larga distancia en beneficio de pensión e indicación de readaptación profesional por el Instituto Nacional de Seguridad Social (INSS) buscando factores y sus percepciones relacionados con el proceso de la enfermedad laboral. En investigación cualitativa, fueron entrevistados individualmente trece camioneros, masculinos, entre 30 y 58 años. En los relatos identificaron-se categorías como características y condiciones de trabajo, expectativas y ganancias profesionales y aplazamiento de la atención. Revelo-se la percepción de la ausencia del trabajo relacionado a la organización actual de los transportes por carretera; y que la licencia por enfermedad ocurriera más tarde con el empeoramiento de morbilidades, evidenciando la influencia de los modos de enfrentamiento de la enfermedad en este proceso. Señaló-se necesidad de mejora constante de acciones de la Seguridad Social, principalmente sobre las especificidades de grupos profesionales en el servicio de rehabilitación del INSS.
\end{abstract}

Palabras clave: bienestar social; salud ocupacional; jubilación; condiciones de trabajo; transportes.

\section{INTRODUÇÃO}

A Previdência Social compreende um conjunto de normas que organizam a forma de proteção do trabalhador contribuinte quando este, por qualquer razão, apresenta perda ou redução da capacidade de trabalho, de forma a prejudicar sua subsistência e a de seus familiares. Dentre os programas do seguro social prestados pelo Instituto Nacional do Seguro Social (INSS), o serviço de reabilitação profissional visa proporcionar aos seus beneficiários, incapacitados parcial ou total para o trabalho, os meios indicados para o reingresso no mercado de trabalho e no contexto em que vivem. Neste artigo, procurou-se descrever as percepções que motoristas de caminhão de rota longa, afastados pelo INSS por incapacidade para essa profissão e com indicação de reabilitação profissional, têm dos processos que conduziram a seu afastamento. Para tanto, descreve-se, entre outros, aspectos do trabalho que para eles estão relacionados ao processo de adoecimento, bem como suas estratégias para enfrentar tal condição.

Os conceitos de deficiência e incapacidade, utilizados por profissionais do INSS para afastar contribuintes de suas atividades profissionais e encaminhá-los para atividades de reabilitação profissional, estão ancorados no Decreto no 3.298/99 e na Lei no 7.853/89, que os definem como:

1) deficiência: toda perda ou anormalidade de uma estrutura ou função psicológica, fisiológica ou anatômica que gere incapacidade para o desempenho da atividade, dentro do padrão considerado normal para o ser humano; 2) redução efetiva e acentuada da capacidade de integração social, com necessidade de equipamentos, adaptações, meios ou recursos especiais para que a pessoa com deficiência possa receber ou transmitir informações necessárias ao seu bem-estar e ao desempenho de atividade a ser exercida (Simonelli, Camarotto, Bravo, \& Vilela, 2010, p. 66).

A despeito de ser uma definição ampla, embora relativamente vaga, Simonelli et al. (2010) sustentam que os manuais de perícia média do INSS 
restringem tais conceitos a critérios que levam em consideração unicamente os determinantes físicos da incapacidade e que, portanto, estão limitados ao modelo biomédico. Desse modo, as práticas periciais daquela instituição tendem a definir as incapacidades dos trabalhadores unicamente a partir dos agravantes físicos que estes apresentam, não sendo avaliadas as questões sociopolíticas da incapacidade (G. S. H. Santos, 2015).

Alternativamente, Simonelli et al. (2010) sugerem, a partir da Classificação Internacional de Funcionalidade, Incapacidade e Saúde (CIF), outra concepção de incapacidade, de viés interacionista e que articula tanto os modelos biomédicos quanto os socioambientais: a incapacidade não é uma condição ou atributo individual definitivo, mas a resultante de uma interação, determinada pelo contexto socioambiental, entre a pessoa e o meio em que vive e atua, e que define o modo como essa pessoa, com funções e estruturas anatomofisiológicas e psicológica singulares, realiza suas atividades cotidianas e participa da vida social, dificultada, ou facilitada, por fatores ambientais (Simonelli et al., 2010).

Reconhece-se nesse modelo o papel central do contexto socioambiental como parte do estado funcional dos indivíduos em suas atividades cotidianas e sociais, mas não se ignora as condições físicas e psicológicas das pessoas. Esse conceito amplia a compreensão do afastamento, que deixa de ser um problema exclusivamente individual e físico, e passa a reconhecer "a interação entre a disfunção apresentada e o contexto ambiental onde as pessoas estão inseridas" (Simonelli et al., 2010, p. 69).

A partir desses pressupostos, deve-se relacionar as condições em que se dão o afastamento do trabalho ao contexto em que a pessoa vive. No que tange à contemporaneidade, podemos relacionar os processos de afastamento a mais recente onda de mundialização do capital industrial, que produziu profundas transformações no mundo do trabalho, por meio da sua complexificação, heterogeneização e fragmentação (Antunes, 2015). Antunes aponta esta múltipla processualidade em um cenário contemporâneo, a começar pela diminuição da classe operária industrial taylorista tanto em consequência do quadro econômico recessivo como da introdução da automação, da robótica e da microeletrônica.

As transformações no mundo do trabalho a partir dos anos 1990 tiveram fortes repercussões em países do Terceiro Mundo, especialmente naqueles com um parque industrial significativo, como é o caso do Brasil (Antunes, 2015). A partir daí, a classe trabalhadora brasileira passou a se mostrar ainda mais heterogênea e multifacetada, agrupando trabalhadores estáveis e precários, qualificados e desqualificados, empregados e desempregados, diferenças geracionais e de gênero, estratificações e fragmentações acentuadas pelo processo crescente de internacionalização do capital (Antunes, 2015).

Diante dessas transformações de caráter duplo e paradoxal, que ora se revelam no intenso envolvimento requerido ao trabalhador e ora na sua 
insegurança no emprego, faz-se necessária uma noção cada vez mais ampliada do trabalho, principalmente no setor de serviços, no qual também foram incluídas novas estratégias nos modos de organizar o trabalho (Antunes, 2015). Neste contexto, torna-se oportuno destacar a reestruturação do transporte rodoviário de cargas uma vez que novas características foram incorporadas a esse ramo de atividade a partir da reorganização do sistema de produção (Nunes, 2011).

A modernização das empresas deste setor se inicia no Brasil a partir de 1990 com a introdução da "logística" de transportes, que mobiliza e intensifica a "terceirização" ou a "subcontratação" na oferta de serviços pelas empresas transportadores, e na execução do transporte nos padrões das novas formas de produção e organização do trabalho contemporâneo, tais como a produção ondemand e just-in-time (M. M. Santos, 2007). Assim, dentre as mudanças significativas introduzidas na organização do trabalho, destaca-se o maior controle do tempo da atividade do motorista (Kapron, 2012).

Nesse entremeio, vale destacar que o desenvolvimento e agravamento das morbidades em caminhoneiros estão documentados em estudos no âmbito teórico-técnico nacional, tendo se relacionado diretamente a jornadas extensas de trabalho, exigências no cumprimento dos prazos de entrega, ausência de pausas para descanso, horário irregular de trabalho, trabalho no turno noturno, hábitos de alimentação não saudáveis (Fogaça, Santos, Souza, \& Morais, 2011; Marqueze, Ulhôa, \& Moreno, 2012). Além disso, o consumo de bebidas alcoólicas e droga como inibidores do sono, por parte desses profissionais, também está associado às condições de trabalho, às exigências de transporte de carga de horário e às grandes distâncias diárias percorridas, não se inscrevendo somente na cadeia de fatores de risco à saúde, mas também como principal fator relacionado à alta prevalência de acidentes de trânsito (Cerqueira et al., 2011; Nascimento, Nascimento, \& Silva, 2007). Outro aspecto importante refere-se à associação do consumo de rebite às faixas etárias mais jovens, sinalizando uma maior vulnerabilidade desses trabalhadores a acidentes de trânsito, possivelmente em decorrência do seu pouco tempo de profissão e que tem acarretado maiores dificuldades em lidar com as pressões no trabalho (Knauth, Pilecco, Leal, Seffner, \& Teixeira, 2012).

A associação entre sono, idade, cansaço, obesidade e longas jornadas de trabalho foi identificada por alguns estudos que avaliam a qualidade de vida dos caminhoneiros (Souza, Paiva, \& Reimão, 2008). Além disso, outros resultados evidenciam que a jornada extensa de trabalho também é considerada como fonte de estresse, estando associada a distúrbios psíquicos menores (Ulhoa et al., 2010). Por outro lado, vale ressaltar o estímulo a longas jornadas de trabalho em razão do valor de pagamento do frete estipulado por tarefa e carga, conforme foi demonstrado no estudo de Knauth et al. (2012). 
Nota-se ainda uma tendência geral dos estudos epidemiológicos em valorizar os hábitos de vida e aspectos objetivos do trabalho, verificando-se que em geral partem da antecipação da previsibilidade de fenômenos e comportamentos (Ruiz \& Araújo, 2012). Esses estudos tendem, por sua característica predominantemente quantitativa, a focalizar mais aspectos objetivos do processo de adoecimento (prevalência e incidência), sendo mais raros deterem-se sobre os modos como os trabalhadores vivenciam esses processos de adoecimento. Além disso, poucos estudos têm investigado as particularidades da atividade de caminhoneiros para além da dimensão prescritivo-normativa, conforme sugerem os teóricos das linhagens ligadas à Ergonomia francófona, que afirmam que as dimensões da atividade real, inevitavelmente distintas das tarefas prescritas, têm efeitos importantes na configuração dos quadros de saúde dos trabalhadores (Falzon, 2007). Finalmente, verificam-se limites na contribuição dos conhecimentos produzidos por meio desses artigos, calcados quase que exclusivamente em abordagens epidemiológicas quantitativas, para o esclarecimento de ações de profissionais da previdência que lancem mão do modelo de incapacidade laboral baseado na CIF e de caráter mais interacionista e socioambiental.

Assim, visando contribuir para melhor compreensão dos processos de produção da incapacidade laboral de motoristas de caminhão de longa rota, incluindo-se nessa análise própria perspectiva dos trabalhadores, realizou-se este estudo com o objetivo de investigar como se configura o afastamento do trabalho desses trabalhadores de modo a conhecer aspectos das condições e organização do trabalho de quando estiveram ativos, bem como alguns dos fatores que conduziram ao adoecimento e à interrupção dessa atividade profissional e o modo como perceberam e vivenciaram tal processo de adoecimento.

Baseado nos conhecimentos construídos a partir da experiência deste grupo profissional, pode-se vislumbrar desdobramentos práticos dessa pesquisa nas ações desenvolvidas pela Previdência Social, entre as quais o serviço de reabilitação profissional. Alterações se fazem necessárias nessa instituição na medida em que, como alguns sugerem, o serviço de reabilitação profissional vinculado ao sistema previdenciário brasileiro vem se demonstrando ineficiente e tem se caracterizado por práticas que, em geral, se distanciam da proteção social dos trabalhadores (Maeno \& Vilela, 2010; Takahashi, Kato, \& Leite, 2010). Frequentemente tais práticas têm se limitado ao encaminhamento, orientação e acompanhamento escolar dos segurados, além do encaminhamento e acompanhamento para/de cursos de qualificação e aperfeiçoamento profissional em diversas áreas de interesse (Bregalda \& Lopes, 2011).

Ademais, as mudanças no modelo de reabilitação profissional brasileiro não se configuram como favoráveis à construção de uma política pública com ações efetivas na inserção do trabalhador em um trabalho que permita sua 
integração social plena (Maeno \& Vilela, 2010). Nesse sentido, é relevante destacar que a atual configuração do serviço de reabilitação profissional prestado pelo INSS aponta para as seguintes problemáticas: de um lado, as abordagens biomédicas que norteiam as diretrizes desse programa as quais acabam por distanciar de suas práticas a dimensão psicossocial dos trabalhadores que vivenciam tal processo (Simonelli et al., 2010); e de outro, o cenário de adversidade dos trabalhadores no qual prevalece os prejuízos à saúde e o agravamento das incapacidades, o que torna imperativo neste contexto a compreensão do mundo do trabalho contemporâneo e a construção de uma política pública de reabilitação profissional, tal como propõem Maeno e Vilela (2010, p. 87), que envolver:

a inserção da saúde do trabalhador nas políticas de desenvolvimento econômico; a desconstrução da cultura e da máquina previdenciária voltada para os custos; a real articulação da Saúde e da Previdência Social em projetos nacionais e locais; a inclusão do caráter distributivo nos planos de modernização; o monitoramento da trajetória dos trabalhadores; e a transparência institucional.

\section{MÉTODO}

A pesquisa, de abordagem qualitativa, ocorreu no Estado do Espírito Santo junto a motoristas de caminhão de rota longa em benefício previdenciário e com indicação de reabilitação profissional pelo INSS. Tal abordagem apresentou-se mais adequada ao alcance dos objetivos abordados possibilitando compreender os significados que tais profissionais atribuem à sua experiência de adoecimento e de afastamento do trabalho. Para tanto, optou-se por percorrer um caminho metodológico guiado pela perspectiva epistemológica centrada na produção discursiva dos participantes, que nesta pesquisa se centra não apenas nos porquês do adoecimento e afastamento, mas, sobretudo na maneira como os trabalhadores perceberam e vivenciaram a produção de tais condições em seus cotidianos. Visa-se com isso apreender os elementos que configuram tal vivência e que é perpassada tanto pela experiência laboral desses caminhoneiros quanto, inevitavelmente, pelo modo como compreendem e produzem o mundo social para além do trabalho (Pope \& Mays, 2009). Os significados produzidos pelos trabalhadores sobre suas vivências foram reinterpretados à luz de produções teóricas que contribuem não apenas para descrever suas experiências cotidianas, mas também para compreender sua formação e relacioná-las a sistemas explicativos que dão indícios de como agir para transformá-las. Entre tais teóricas, destacam-se as ligadas à linhagem da Ergonomia francófona que têm na atividade de trabalho seu conceito central (Falzon, 2007).

Por meio dessa abordagem, contribui-se para que pesquisadores e profissionais de sistemas previdenciários possam atuar de maneira mais eficaz em conjunto com caminhoneiros afastados em prol da melhoria das suas 
condições de vida. Isso porque por meio de pesquisas como essas, os profissionais do INSS podem melhor conhecer o conjunto de significados que os usuários do serviço produzem para dar sentido a suas vidas, permitindo a construção de relações calcadas em pactuações e referências discursivas comuns.

\section{Participantes}

A amostra, de conveniência, foi composta por 13 trabalhadores do sexo masculino distribuídos em três agências do INSS/ES, das cidades de Aracruz, Linhares e Vitória. Dos treze entrevistados, seis tinham na ocasião da entrevista idades entre 50 e 55 anos, quatro entre 40 e 45 anos e dois com mais de 55 anos. Apenas um dos entrevistados tinha menos de 35 anos de idade. Sete deles nasceram em localidade rural e seis em área urbana. A maioria declarou ser casado ou manter união estável e possuir filhos.

Quanto à escolarização, sete possuem ensino fundamental incompleto, cinco possuem ensino médio incompleto, e um concluiu recentemente o ensino médio. No momento em que as entrevistas foram realizadas, seis participantes haviam retomado o ensino fundamental por orientação do programa de reabilitação profissional do INSS, ao passo de que outros dois haviam retomado seus estudos por interesse próprio, ambos no ensino médio. O participante que recentemente concluiu o ensino médio também o concluiu por seu próprio interesse, após ter sido afastamento por adoecimento. Nenhum dos participantes cursava, naquele momento, outros cursos profissionalizantes sugeridos pelo programa.

No que tange ao tempo de afastamento do trabalho dos entrevistados cinco participantes se encontravam afastados do trabalho entre 1 e 3 anos, quatro participantes estavam nessa condição entre 4 e 5 anos e três deles com mais de 7 anos. Um dos participantes estava afastado do trabalho há 02 meses, no entanto informou outro afastamento anterior pelo mesmo motivo de saúde há 8 meses desse último.

\section{Instrumentos e procedimentos}

Em função das peculiaridades do objeto desse estudo - percepção que os próprios motoristas de caminhão de rota longa possuem de seu afastamento do trabalho- utilizou-se a entrevista com roteiro semiestruturado de modo a possibilitar ao entrevistado discorrer sobre aspectos da profissão e das condições de trabalho bem como sobre o processo de afastamento. A elaboração de um roteiro e procedimento de entrevista foi fundamentada no método fenomenológico para pesquisa em psicologia social, tal como o descrevem Trindade, Menandro, e Giarnórdoli-Nascimento (2007). O uso do roteiro foi fundamental para a realização da entrevista em razão da diversidade de acontecimentos que se exprimem no relato da experiência vivida e que 
direcionam o pesquisador a proceder à análise em profundidade sem necessariamente impor hipóteses analíticas apriorísticas, mas demonstrando um campo referencial comum que permite um diálogo franco e respeitoso entre ele e o participante. Esse roteiro contribui, também, para fazer emergir as unidades de significados que permitiram a posterior elaboração do fenômeno em torno de categorias e subcategorias.

A estruturação do roteiro de pesquisa, ou tópicos-guia, foi precedida de uma revisão crítica da literatura (Gaskell, 2008) realizada através de um levantamento de artigos sobre o tema trabalho e saúde de caminhoneiros. 0 roteiro foi composto por 07 questões fechadas e 13 questões abertas. As questões fechadas objetivavam obter dados sociais (origem, idade, estado civil, se tinham filhos, rendimento financeiro familiar, escolaridade e tipo de relação de trabalho e atividades profissionais anteriores a de motorista de caminhão). Já as questões abertas visavam verificar a opinião dos participantes acerca dos motivos para a escolha desta profissão, das impressões sobre o trabalho em questão, das condições de vida na estrada, das condições de saúde após o ingresso na profissão, sobre como e por quais fatores ocorreu o afastamento do trabalho.

O primeiro contato com motoristas de caminhão com indicação de reabilitação profissional foi realizado por servidores do programa de reabilitação profissional do INSS. Diante da ausência de estatísticas da Previdência Social que informem, por grupo profissional, a concessão do auxílio-doença previdenciário ou acidentário e da não receptividade à pesquisa ao ser realizada busca ativa nos postos de atendimento do INSS, optou-se então pela divulgação dos objetivos do estudo com esses servidores que foram indicando os trabalhadores-alvo da pesquisa.

As entrevistas foram realizadas individualmente no serviço de reabilitação profissional prestado nas unidades do INSS das cidades de Vitória, Linhares e Aracruz. Foram considerados os ambientes de maior viabilidade e/ou preferência do participante bem como sua disponibilidade de horário. Os entrevistados citados no corpo deste texto serão identificados pela letra " $E$ ", seguida do numeral correspondente à ordem das entrevistas.

A pesquisa seguiu padrões éticos estabelecidos na Resolução 466/2012 do Conselho Nacional de Saúde. Em seguida, viabilizou-se o contato com os participantes e mediante a autorização destes, foram agendadas as entrevistas no serviço de reabilitação profissional de três unidades do INSS. Respeitou-se a garantia do anonimato dos depoimentos, mediante a apresentação do Termo de Consentimento Livre e Esclarecido.

Análise dos dados

Para tratamento do material proveniente dos registros verbais da pesquisa realizou-se a análise de conteúdo, de maneira rigorosa e interpretativa. Tal 
método se configura como um conjunto de técnicas de análise das comunicações, que utiliza procedimentos sistemáticos e objetivos de descrição do conteúdo das mensagens (Bardin, 2015). Após a transcrição das entrevistas, iniciou-se a primeira leitura de todo o material textual produzido pelos entrevistados (Bardin, 2015) para apreensão global das ideais principais e seus significados gerais e estabelecimento de códigos provisórios.

A efetiva exploração do material se iniciou com a identificação de conteúdos semelhantes no texto dos entrevistados, que foram grifadas por meio do uso de cores (Franco, 2012). Tais conteúdos se referem a temas que foram considerados como a unidade de análise. Cada cor utilizada gerou uma tabela para os temas identificados. Ao final do agrupamento das unidades de registro, foi realizada uma nova leitura a fim de se identificar um nome que representasse o conteúdo de cada tabela. Após essa rotulagem, organizou-se os temas em uma segunda tabela a partir da diversidade de categorias e subcategorias estabelecidas a posteriori e que foram baseadas nos temas que emergiram durante o próprio relato dos participantes, destacados também em função de sua riqueza e relevância para o estudo (Campos, 2004).

Esclarece-se que o material textual sobre o qual se constituem os temas, categorias e subcategorias refere-se ao conjunto das 13 entrevistas realizadas, não se requerendo que um tema, categoria ou subcategoria tenha se repetido entre todos os participantes para que tenha sido identificado.

Por fim, as análises produzidas pela análise de conteúdo foram problematizadas a luz da Ergonomia Francófona (Falzon, 2007), da Clínica da Atividade (Clot, 2010) e da Psicodinâmica do Trabalho (Dejours, 2012, 2015).

\section{RESULTADOS E DISCUSSÃO}

A partir da análise de conteúdo geraram-se os eixos temáticos apresentados na Tabela 1 abaixo, com suas respectivas categorias e subcategorias, discutidos a seguir.

Expectativas para o ingresso e permanência na profissão e percepção de suas transformações

O histórico profissional dos participantes revelou que a atividade de motorista de caminhão foi considerada sua principal escolha dentre outras atividades por eles desempenhadas. Nos relatos em que a vida laboral se iniciou em atividades no campo ou naquelas com baixos rendimentos quando comparados à profissão de caminhoneiro, evidenciou-se que a busca por melhores condições de renda e ascensão social e ocupacional constituíram as principais motivações para ingresso nessa profissão, devendo-se apontar ainda que o baixo nível educacional também se interpõe nesse processo: "Eu sou do interior, eu vim de classe baixa, né! (...) Eu comecei com trator em fazenda (...). 
Depois, fui pra cidade e comecei é... Com a carreira como caminhoneiro, né! (E6)"; ou ainda: "Eu acho que é feito assim: aquela pessoa que não tem estudo, e pra ganhar um pouquinho a mais não resiste geralmente ao caminhão, né? (...) (E11)".

Tabela 1.

\begin{tabular}{|c|c|c|}
\hline Eixos temáticos & Categorias & Subcategorias \\
\hline 1. Escolha profissional & $\begin{array}{l}\text { 1.a Motivos para o } \\
\text { ingresso na profissão }\end{array}$ & \\
\hline \multirow[t]{3}{*}{$\begin{array}{l}\text { 2. Experiência de } \\
\text { trabalho }\end{array}$} & $\begin{array}{l}\text { 2.a Percepções acerca do } \\
\text { trabalho }\end{array}$ & $\begin{array}{l}\text { 2.a.1 Mudanças após o } \\
\text { ingresso na profissão }\end{array}$ \\
\hline & & $\begin{array}{l}\text { 2.a.2 A imagem do } \\
\text { motorista de caminhão }\end{array}$ \\
\hline & & $\begin{array}{c}\text { 2.a.3 Significados da } \\
\text { atividade }\end{array}$ \\
\hline \multirow[t]{6}{*}{$\begin{array}{l}\text { 3. Configuração da } \\
\text { atividade do motorista de } \\
\text { caminhão de rota longa }\end{array}$} & $\begin{array}{l}\text { 3.a Características da } \\
\text { profissão }\end{array}$ & $\begin{array}{l}\text { 3.a.1 Variabilidade de } \\
\text { cargas no transporte } \\
\text { rodoviário }\end{array}$ \\
\hline & & $\begin{array}{c}\text { 3.a.2 Remuneração: } \\
\text { salário fixo, comissão por } \\
\text { produtividade }\end{array}$ \\
\hline & $\begin{array}{l}\text { 3.b Condições de } \\
\text { trabalho }\end{array}$ & $\begin{array}{l}\text { 3.b.1 Aspectos } \\
\text { relacionados às condições } \\
\text { de vida na estrada }\end{array}$ \\
\hline & & $\begin{array}{c}\text { 3.b. } 2 \text { Elementos } \\
\text { referentes a valores } \\
\text { mercantis }\end{array}$ \\
\hline & & $\begin{array}{l}\text { 3.b. } 3 \text { Relatos sobre uso } \\
\text { de drogas e acidentes }\end{array}$ \\
\hline & & $\begin{array}{l}\text { 3.b. } 4 \text { Aspectos } \\
\text { organizacionais }\end{array}$ \\
\hline
\end{tabular}

\begin{tabular}{cc}
\hline 4. Saúde e Trabalho & $\begin{array}{c}\text { 4.a Concepção de saúde: } \\
\text { homem-máquina }\end{array}$ \\
\hline 5. Impactos do & 5.a Dos primeiros \\
adoecimento na & episódios indicativos de \\
danos à saúde à \\
incapacidade laboral \\
interrupção do trabalho \\
5.b Fatores atribuídos ao \\
adoecimento \\
5.c Relatos de adiamento \\
do cuidado à saúde \\
5.d Afastamento do \\
trabalho
\end{tabular}

Eixos temáticos, categorias e subcategorias da análise de conteúdo 
Também foram destacados motivos pessoais para o ingresso nesta profissão tais como o sonho de criança de ser motorista de caminhão e o desejo de conhecer lugares diferentes: "E acho que é o sonho de toda criança, né! Quando nasce é..., a gente dá o carrinho pra ele pra brincar (...) (E4)".

$\mathrm{Na}$ direção dos estudos de Januzzi (2002), estes resultados sugerem que as mudanças estruturais no Brasil decorrentes da industrialização teriam propiciado expectativas para a mobilidade social, ocasionando a expansão dos centros urbanos e, em consequência, a formação de uma classe média com crescente poder de consumo. Frente a isso, potencializou-se a necessidade do transporte rodoviário por todo o país, e o consequente aumento da oferta de trabalho neste setor (Scaramella, 2004). Assim, nos anos 70 e 80, a imagem do caminhoneiro "bandeirante e desbravador" (Rosa, 2006, p. 84) esteve associada à ideia de progresso do Brasil com o intuito de legitimar a política rodoviária sob o mérito de "transportar as riquezas do país".

Em consonância com essa imagem atribuída ao caminhoneiro no referido período, chama atenção a liberdade e o prazer por dirigir e conhecer lugares e pessoas como motivos para a permanência na profissão: "A gente gosta dessa vida, porque é... uma liberdade que você não tem em outro lugar. Se você for trabalhar numa indústria, você tem hora pra entrar, e hora pra sair. Você tem a, a... o seu uniforme (...) (E9)"; "Ele faz aquilo por gostar, entendeu? É porque todo dia você tá num lugar diferente, conhece gente diferente, entendeu? Você não tem rotina $(. .).(E 4) "$.

Embora tais características ainda sejam marcantes na profissão, tal como exprimem os participantes, verifica-se que no atual contexto de trabalho dos motoristas de caminhão de rota longa o avanço da tecnologia tem requisitado novos posicionamentos deste trabalhador, seja em relação ao veículo, em relação à formação ou ao trabalho: "Eu aprendi a conduzir com mais (...) mais destreza, né, com mais sabedoria. Conheci máquinas que, se você tá numa categoria, você não conhece, né? Porque são caminhões mais, né, tecnologia mais avançada (E9)".

Essas mudanças vêm acompanhadas de diferentes modos de perceber uma ou outra geração de caminhoneiros. Por exemplo, nas explicações dos trabalhadores sobre as relações entre os distintos modos de conduzir, o tipo de veículo e de carga transportada e a experiência acumulada com o tempo dedicado à condução profissional, verifica-se uma tendência de relacionar a maior capacitação profissional aos trabalhadores mais jovens, fato consequente à mudança de perfil profissional. Aos jovens profissionais, mais bem capacitados, contrapõe-se a figura do caminhoneiro mais velho, que "tem que andar de chinelo, barbudo. Eu conheço vários que nessa idade que é assim mesmo (E8)".

Nota-se que essas referências, além de indicarem posicionamentos divergentes entre os participantes, também evidenciam em um contexto de intensificação do trabalho, conforme destaca Molinié (2002), que os 
trabalhadores mais velhos são os mais afetados com a falta de investimento em formação e desenvolvimento de competências tal como sugere o fragmento de um participante com mais de 50 anos:

Motorista é igual burro de carroça. Só sabe olhar pra frente (...). Ele só olha pro lado quando, pro retrovisor. Ele não tem (...) tempo de dialogar com ninguém (...) de abrir a mente, ele só pensa naquele negócio: eu vou lá, carrego, descarrego, carrego e descarrego só isso (E1).

Outro exemplo destas diferentes percepções sobre distintas gerações de caminhoneiro refere-se ao comportamento imprudente de pares no trânsito (tabela 1, subcategoria 2.a.2), atribuído principalmente aos caminhoneiros mais jovens, fenômeno também observado entre os motoboys mais velhos em relação aos mais jovens (Moraes \& Athayde, 2014). Alguns participantes relacionam também o aumento de acidentes e uso de substâncias psicoativas com o ingresso de pessoas jovens neste ramo de atividade, aspecto ressaltado também em outras pesquisas (Knauth et al., 2012).

A despeito das distintas realidades vivenciadas por participantes com diferentes faixas etárias, verifica-se que suas expectativas profissionais quando do ingresso nesta atividade foram, para eles, relativamente corroboradas pelas oportunidades de melhoria salarial e mobilidade social. Entre outros, tais aspectos contribuem para a permanência de trabalhadores na profissão ao longo do tempo, contribuindo para a produção de identidades profissionais e fortalecimento do ofício, na medida em que intensificam a produção e partilha de gêneros profissionais (Moraes, Rohr, \& Athayde, 2015). Por gênero se compreende aqui uma espécie de memória transpessoal que organiza, reconfigura e orienta a ação de trabalhadores que pertencem a um coletivo de trabalho no meio em que realizam suas tarefas, contribuindo para que estes as execute de modo a permitir reduzir os custos da tarefa, facilitar o intercâmbio entre trabalhadores, evitar erros e construir, em torno da partilha dessa memória e de experiências de vida, processos identitários, modos de produzir saúde e a caracterização do ofício (Clot, 2010).

Por outro lado, verifica-se que algumas dessas expectativas apresentaramse atreladas a discursos relacionados ao fenômeno do afastamento do trabalho, tal como, por exemplo, a tolerância por situações de trabalho penosas, em parte sustentadas e justificadas por percepções, perspectivas e valores positivos em relação à profissão, tais como o sentimento de liberdade e o prazer por dirigir e conhecer novos lugares (tabela 1, subcategoria 2.a.3). Essas percepções, expectativas e valores positivos, aliadas aos benefícios financeiros da profissão, contribuem para compensar, cognitivamente, os riscos de adoecimento, acidente e sofrimento observados a partir do ingresso na atividade. Esse processo se dá conforme uma lógica em que os benefícios, riscos e custos de uma atividade são sopesados pelos trabalhadores por meio de análises sociocognitivas, mais ou 
menos inconscientes, visando dar sentido e justificativa à atividade que se executa - e a suas condições, muitas vezes deletérias - tal qual se demonstrou junto a outra categoria profissional dos transportes terrestre (Veronese, 2004).

Configuração da atividade do motorista de caminhão de rota longa: características e condições de trabalho

Identifica-se para além das tarefas de condução propriamente dita a realização de outras tarefas por parte do caminhoneiro. Entre estas, algumas tarefas relacionadas ao manejo da carga - como conferência, amarração, acompanhamento de sua acomodação e descarregamento -, tarefas relacionadas à manutenção do veículo - tais como a inspeção do veículo -, e tarefas administrativas, como a conferência de notas fiscais e recebimento do pagamento.

Essas múltiplas tarefas fazem parte do conjunto de ingredientes que intensificam a imensa variabilidade que caracteriza o transporte rodoviário (Forzy, 2007). Entre os diversos elementos que contribuem para a variabilidade da atividade de transporte encontram-se a grande variedade de tipos de cargas transportadas, tal qual indicam os participantes: carga perecível, carga seca, carga perigosa e carga indivisível - tais como grandes equipamentos, bobinas, etc. Destaca-se como outro ingrediente que aumenta a variabilidade do transporte rodoviário de cargas e com grande influência nos modos de condução e seus efeitos, o que os trabalhadores denominam de carga de horário, atribuída às cargas com prazos determinados para entrega: "Verdura! E verdura é... com os perecível, né! Você precisa tá andando muito. Porque é uma carga de horário (...). Você quase num tem parada (...). Era tudo cronometrado: se atrasasse lá, o chefe cá tava sabendo (E5)".

O tempo da carga se torna elemento chave na compreensão dos modos como se executa uma atividade, sobretudo porque a remuneração dos caminhoneiros entrevistados é uma combinação de salário e comissão, ressaltando as influências da valorização da eficiência econômica no transporte rodoviário de cargas, o que determina suas condições de trabalho: "Por exemplo, meu salário era salário do sindicato, que era mil quatrocentos (...). Então, é... quanto mais a gente trabalhasse, mais a gente ganhava, entendeu?(...). Mas isso desgasta muito a gente (E9)". Em contrapartida, tais condições determinam também, aos olhos dos trabalhadores, o processo do que denominam de "desgaste", referindo-se ao fato de que a saúde é afetada negativamente pelo excesso de trabalho e de controles, geralmente calcados na gestão do tempo.

O ganho por comissão contribui não só para a intensificação da carga horária de trabalho, mas também para propiciar determinados modos de condução e concorrência entre pares, também intensificada pela defasagem do valor do frete (tabela 1, subcategoria 3.b.2). Aliado a isso, apontou-se a difícil concorrência no mercado de trabalho com caminhoneiros mais jovens em razão 
da preferência que muitas empresas têm pela contratação de trabalhadores com menos idade:

E se você não der o que ela quer você tá fora da equipe, e tem dez lá fora querendo ocupar o seu lugar, entendeu? Hoje, a maioria das empresas hoje, ela quer rapaz novo ai de vinte e três até seus trinta anos, que guenta rojão (E10).

Tais questões que emergem em torno da remuneração parecem interligarse ao sentimento de desunião e desconfiança entre os pares (tabela 1, subcategoria 2.a.2), o que para Dejours (2012) está relacionado às novas formas de organização do trabalho, de gestão e direção das empresas. Tais modos de gerenciamento contemporâneo se dão sob o princípio da individualização, convocando a concorrência generalizada entre os trabalhadores, o que resulta em "condutas desleais entre pares e à ruína das realizações solidárias" (p.43). Essa condição intensifica a fragilização dos coletivos, contribuindo para a dificuldade de construção e partilha de estratégias coletivas para o enfrentamento das condições e características deletérias de trabalho.

Ainda em relação à remuneração por produção, destaca-se que os ganhos adicionais obtidos nos períodos de maior movimentação de cargas não são incorporados ao auxílio doença-previdenciário (tabela 1, categoria 5.d), acarretando em menor rendimento mensal durante o período de afastamento do trabalho. Esse elemento contribui para a produção de outro aspecto que chama atenção nos relatos dos participantes, que é o comportamento de adiamento do cuidado à saúde, antecedendo a interrupção do trabalho. Este adiamento tem como consequência o agravamento do quadro de saúde na maioria deles: "Eu sentia dor aqui, mas não ligava muito não. Depois que eu encostei, ai fui fazer os exame. Já não tinha mais jeito de tratar com medicamento, eu tinha que fazer cirurgia (...) (E2)".

Além das características dessa atividade, os participantes referiram-se a um conjunto de condições de trabalho que também influem em sua saúde. Estas condições foram identificadas sob duas perspectivas: de um lado, aquela que retrata o ambiente de trabalho através de locais inapropriados para refeições, além da necessidade de custeio do cuidado pessoal sob as regras dos postos de gasolina. De outro, o contexto organizacional do transporte de cargas que parece determinar a falta de tempo para necessidades vitais como alimentação e sono, principalmente em decorrência das exigências de cumprimento dos prazos de entrega ocasionadas pelo tipo de carga transportada.

Decorrem daí mudanças percebidas em seu próprio corpo após o ingresso na profissão, tais como a diminuição ou aumento do peso corporal (tabela 1 , subcategoria 2.a.1), corroborando pesquisas realizadas em outras regiões (Marqueze et al., 2012). Essas alterações físicas estão parcialmente relacionadas a seus modos de viver e trabalhar - trabalhar sentado, ingestão de alimentos calóricos, etc. -, porém são também percebidas como consequências das 
exigências da organização empresarial e de gestão deste setor, através da intensificação da carga horário de trabalho, do cumprimento dos prazos de entrega e espera da carga (tabela 1, subcategoria 3.b.4): "Eu percebi. Porque, eu acabei engordando mais, né? Porque eu não era assim... (E11)"; "Emagreci porque (...) você não tem hora pra almoçar, não tem hora pra jantar. Você não tem aquele cardápio assim, onze horas eu vou parar pra almoçar (E3)". Até mesmo o uso do tempo livre tende a estar condicionado às tarefas de trabalho que se evidencia na ausência do efetivo lazer nos finais de semana, em função das exigências deste setor (tabela 1, subcategoria 3.b.4).

Essas condições explicam-se fundamentalmente pela introdução da logística de transportes desde 1990, transformando as práticas organizacionais neste setor, intensificando nos trabalhadores os efeitos acima mencionados. Isso porque o atual processo de movimentação de cargas por transporte rodoviário estrutura-se em princípios da rentabilidade e competitividade, sendo efeitos do sistema just in time e produção on-demand por parte da indústria nacional, que busca "o melhor aproveitamento possível do tempo de produção (incluindo-se também o transporte, o controle de qualidade e o estoque)" (Antunes, 2015, p. 26). Neste sistema, a lógica é sempre a da redução de custos e economia dos meios, da urgência e da excelência. Resta aos trabalhadores se adequarem a essa lógica ou ficarem sem emprego.

Outros elementos que também parecem ser determinados por esta lógica empresarial referem-se à necessidade do uso de inibidores do sono para o cumprimento dos prazos de entrega da carga, bem como as estratégias de adequação do sono, como, por exemplo, o aproveitamento do tempo para dormir durante as paradas de fiscalização. Nesta perspectiva, o estudo de Nascimento et al. (2007) demonstrou que apesar da consciência dos caminhoneiros acerca dos prejuízos à saúde provocados pelo uso de inibidores do sono, seu uso foi considerado como necessário em decorrência da extensa jornada de trabalho e necessidade de entrega da carga no prazo determinado.

Impactos do adoecimento na capacidade para o trabalho

Os relatos sobre o período compreendido entre o início dos sintomas ou lesões e a interrupção do trabalho perpassando pela necessidade de percepção do auxílio-doença previdenciário conduziram à construção da categoria dos primeiros episódios indicativos de danos à saúde à interrupção do trabalho (tabela 1, categoria 5.a), na qual evidenciam-se os impedimentos de se prosseguir na atividade de caminhoneiro:

Quando eu cheguei na fábrica, começou a adormecer minha, minhas costas e minhas perna... (...). Ai eu queria descer do caminhão, quase não consegui. Ai fui devagarzinho, desci. Ai liguei pro meu parceiro, eles me levaram embora, eu fui pro hospital (...). Ai, depois daquilo ali, acabou pra mim (E10). 
A partir dos relatos em torno dessa temática foram identificados também os Fatores atribuídos ao adoecimento (tabela 1, categoria 5.b), destacando-se entre estes: o intenso ritmo de trabalho conjugado, por vezes, às exigências de produtividade ou a necessidade por manter determinado padrão de rendimentos. Também foram mencionados outros elementos relacionados aos hábitos de vida adotados, tais como o sono, a alimentação e o uso de inibidores do sono, bem como o esforço físico e a manutenção prolongada da postura sentada.

Vale ressaltar as doenças mencionadas pelos participantes como responsáveis por sua interrupção do trabalho, destacando-se as doenças oculares, afecções da coluna e lesões ortopédicas. Também foram relatadas as cardiopatias, lesões cerebrais e menos frequentemente distúrbios mentais e distúrbios metabólicos.

Os elementos acima descritos que aparecem envolvidos nas reconfigurações contemporânea do trabalho do motorista de caminhão de rota longa, além de resultantes das novas formas de organização do trabalho, também sinalizam o aumento da produtividade com repercussões na saúde dos trabalhadores, tal como verificado na categoria Fatores atribuídos ao adoecimento, e corroboram outras pesquisas realizadas no país (Fogaça et al., 2011). Embora estes fatores sejam tradicionalmente analisados a partir do estabelecimento de uma relação causa-efeito, se compreendidos na problemática das relações idade-trabalho em um contexto de intensificação do trabalho, percebe-se que as condições de execução da atividade do caminhoneiro têm implicações na diminuição de suas capacidades, caracterizando assim o envelhecimento pelo trabalho (Ramos \& Lacomblez, 2005), tal como exemplifica o trecho: "Quando é novo, a pessoa aguenta tudo, né! Mas quando vai chegando uma certa idade seu corpo já não tá mais correspondendo por mais que você se esforce pra isso(...) (E5)".

Chama a atenção o fato de que tal relação, entre excesso de trabalho e o que denominam de "desgaste" é percebida pelos trabalhadores, mas estes não encontram estratégias para fazer face a essa situação. Essa incapacidade se deve, de um lado, pelo fato de haver uma concorrência desigual entre os trabalhadores com mais idade e os mais jovens, que são preferidos pela organização, levando os trabalhadores com mais idade a não demonstrar fragilidade em suas tarefas - por meio de licenças médicas, por exemplo - para não perder sua atratividade mercadológica. Isso contribui para que eles adiem, ao máximo possível, os cuidados pela saúde. Por outro, porque são remunerados por produtividade, o que significa que tempo parado é período com rendimento menos, eles tendem a evitar o máximo possível o afastamento das pausas.

Analisando essas questões na perspectiva de que a saúde é mobilizada no domínio do gênero profissional, dado o seu caráter de mediação da tradição e da constante renovação nas ações de cada um (Clot, 2010), os conflitos geracionais, o adoecimento de trabalhadores e a dificuldade de fazer face a essas condições 
são indícios de que o gênero profissional partilhado por esses profissionais está enfraquecido. Esse enfraquecimento é outro indício da fragilização dos coletivos acima apontado, que pode produzir efeitos na luta pela transformação do trabalho e a vivência de um trabalho produtor de saúde.

Em contrapartida, o enfraquecimento do gênero profissional dos caminhoneiros não deve ser confundido com sua eliminação ou inexistência. Isso porque, como dito acima, os participantes revelaram que seu histórico e experiência profissional, seu saber-fazer adquirido e mesmo o avanço da idade nesta profissão contribuem para um processo de seu desenvolvimento pessoal e profissional, sendo, também um fator fundamental para o desenvolvimento de competência singulares e coletivas (Ramos \& Lacomblez, 2005). Essa dimensão, além de ser um contributo para a construção de dimensões identitárias profissionais (Moraes et al., 2015), dão pistas da importância de se reinterpretar os processos de envelhecimento no trabalho de modo a valorizar o acúmulo da experiência, no lugar de diminuições de capacidades físicas ou cognitivas.

De qualquer modo, ressalta-se mais a organização do trabalho do transporte rodoviário de cargas, e não a idade em si, como mais diretamente relacionada a parte considerável das doenças mencionadas pelos participantes. Isso porque a entrega da carga no prazo determinado revela um processo de intensificação do trabalho, que de acordo Seligmann-Silva (2011), constitui um importante fator na manifestação do adoecimento físico, psíquico e emocional. Além disso, como sugere o conceito de incapacidade sustentado por Simonelli et al. (2010), uma incapacidade não deve ser apreendida apenas a partir das características individuais e singulares de uma pessoa, mas do modo como se dá a relação entre essas características e condições pessoais e o meio em que se encontra. Nesse sentido, o envelhecimento só é incapacitante se não se muda as condições de execução da atividade concomitantemente ao envelhecimento do trabalhador. Conforme indicam os caminhoneiros, esse parece ser a condição em que vivenciam suas profissões.

Modos de não lidar com o adoecer: o adiamento do cuidado e o afastamento do trabalho

A resistência física para realização da atividade de motorista de caminhão e o maior vigor na juventude para o seu desempenho foram um dos principais aspectos identificados na categoria Concepção de saúde: homem-máquina (tabela 1, categoria 4.a): "Porque você trabalhar doze horas, dentro de um caminhão, direto, é doído. Você não... chega uma hora que você vai enquanto você tá novo, depois você chega numa época que você não aguenta mais (E2)".

Nota-se que a necessidade de "resistência física" para a execução do trabalho esteve, em geral, mais intimamente ligada à intensificação da carga horária de trabalho: "E quando chega o dia, que você rodou a noite toda (...) que 
é pra você finalizar o seu trabalho, ai vem essa questão da logística (...) você tá lá tendo que entregar a mercadoria (E9)".

Tal característica emerge em dois momentos de distintas demandas para a profissão: durante as décadas de 70 e 80 , quando além dos conhecimentos necessários à condução do veículo, tornaram-se imprescindíveis a força física e outras habilidades diante dos imprevistos e da ausência de recursos de oficina nas estradas (Botelho, Diesel, Adamczyk, \& Zeferino, 2011) e no contexto da introdução da logística de transportes a partir de 1990, quando certas práticas organizacionais pareciam corroborar a "força física" e a "resistência" necessárias para suportar as condições de trabalho, entre eles as duras exigências, as longas jornadas e o tempo exíguo da carga.

Assim, são as características, condições e vivência dos trabalhadores no trabalho que se configuram como eixos centrais na compreensão dos processos de saúde-doença. Aí sua noção de saúde perpassa pela relação que se estabelece com o trabalho. Os modos destes trabalhadores de lidar com o adoecer, que se expressa, sobretudo, por sua relativa negação e pelo adiamento ao máximo do cuidado, se inscreviam em suas atividades antes do afastamento do trabalho. Esse modo de enfrentar o adoecimento sinaliza, ainda que de modo diminuído, para capacidades de criar novas normas em meio à instabilidade das situações de vida e trabalho (Canguilhem, 2011). Paradoxalmente, a recusa ou impossibilidade em se empreender mudanças significativas dos modos de viver o trabalho diante dos sofrimentos inicialmente toleráveis, uma vez que as transformações das características e condições da profissão se mostram particularmente dificultadas, intensificaram tais problemas tornando, para muitos, impossível a continuidade de se realizar essa atividade profissional.

Percebe-se ainda que as características identificadas na categoria Concepção de saúde: homem-máquina aparecem intrinsecamente ligadas à capacidade para o trabalho, o que também corroboraram os comportamentos de adiamento do cuidado à saúde (tabela 1, categoria 5.c) que antecedem o afastamento do trabalho. Nesse sentido, "adiar o cuidado à saúde" reduz o tempo em que o trabalhador não ficará longe do mercado, o que implicaria em perdas financeiras que the são fundamentais. Tal comportamento sinaliza a busca por manter-se em atividade de forma a garantir a realização pessoal, psíquica e socioeconômica (Dejours, 2015), os quais se desvelam nos afetos mobilizados na escolha desta profissão, bem como na ascensão e mobilidade social por ela proporcionada (tabela 1, categoria 1.a). Ademais, a falta de tempo que justifica esse adiamento também parece reforçar a valorização da eficiência econômica no transporte de cargas.

A expressão "Se não parar a máquina, a gente continua, né! (E9)" ilustra o quão importante é a utilidade do corpo neste contexto de trabalho. Na ótica da situação de classe, Boltanski (1979) analisa a valorização da atividade e da força física em grupos populares nos quais o corpo revela-se como um instrumento de 
trabalho ou uma máquina. Nesta perspectiva, a doença representa a falta de força que impossibilita o uso profissional do corpo, sendo então reconhecida quando já não se pode mais desempenhar as atividades rotineiras necessárias à sobrevivência.

O agravamento das morbidades foi outro aspecto identificado que pode ser decorrente do adiamento do cuidado à saúde. Na medida em que o agravamento se constitui como fator determinante na interrupção da atividade laboral dos participantes, prorroga-se o quanto se pode a busca pelos serviços médicos, que só se dá diante da gravidade da doença: "Não teve jeito! Ainda vim dirigindo de lá até aqui, sem conseguir sair do banco (...). Aí parei e comprei os comprimidos, fui tomando... Cheguei aqui, fazendo exame, o médico encostou (E6)". Neste contexto, a figura médica aparece como decisiva na interrupção do trabalho, conforme identificado na categoria Dos episódios indicativos de danos à saúde à interrupção do trabalho (tabela 1, categoria 5.a). Para este grupo profissional a doença se inscreve como fenômeno externo ao indivíduo, e é resultante e dependente da intervenção do profissional médico (Dejours, 2015): "a minha ficha caiu mais ainda quando o médico chegou pra mim, a, a, a, a perita, né! Chegou pra mim e falou assim: 'Nós vamos recolher a tua carteira!' (E7)"; ou ainda "quando fui renovar a habilitação que eu percebi... (...). Fui fazer o exame ali, né! O médico falou: 'Olha, você não pode dirigir mais não!' (E11)".

O conceito de ideologia defensiva proposto por Dejours (2015), também se torna profícuo para aclarar as questões que perpassam pela vivência do corpo na doença. O sentimento de vergonha descrito pelo autor para caracterizar a reação dos trabalhadores frente à doença, esclarece o adiamento do cuidado à saúde relatado pelos participantes. Diante de toda a ansiedade gerada pela doença, institui-se a vergonha como uma ideologia de defesa coletiva contra estar doente e, por conseguinte, de estar incapacitado para o trabalho.

É importante salientar ainda que para contribuir para a ampliação do conceito de trabalho a partir de novos paradigmas, foram introduzidas pelo viés do gênero, questões relevantes que se referem à divisão sexual do trabalho (Hirata, 2002). Assim, os estereótipos de virilidade e feminilidade no âmbito do trabalho são uma das consequências da divisão sexual do trabalho e que em relação aos homens também tem repercussões na produção social do processo saúde-doença: "para os trabalhos masculinos, a exaltação da virilidade e dos estereótipos que Ihes são associados (força, coragem, etc.) permitem balizar uma parte dos riscos e opera, em certas profissões, uma seleção entre os trabalhadores" (Vogel, 2001, p. 13). Neste contexto, a doença pode então despertar a vergonha e as defesas contra ela, por meio da virilidade, diante da ameaça de inutilidade do corpo e sob as quais se delineiam seus modos de lidar com o adoecer. Desse modo, os comportamentos de adiamento do cuidado à saúde, guiados pelo uso profissional do corpo, evidenciam não somente o agravamento dos problemas de saúde, mas também um afastamento do 
trabalho mais tardio com as possíveis marcas da incapacidade e por outro lado a luta por manter-se em atividade. O fato de se tratar de uma profissão eminentemente masculina corroboram para solidificar esse sistema defensivo de tipo ideológico.

Verifica-se, portanto, que o processo de adoecimento dos caminhoneiros é mais vivenciado como uma recusa ou uma "não" vivência de sintomas, problemas físicos ou sofrimentos percebidos ao longo da vida. Adia-se o quanto se pode o tratamento e cuidado de si, parando-se apenas quando o corpo para. Entre outros, porque são muitos os fatores que ocasionam o adoecimento, indo além da governabilidade dos trabalhadores para impor mudanças nessa direção. Conforme demonstrado acima, entre as causas do adoecimento, foram citadas: o excesso de trabalho, calcado, sobretudo, na remuneração por produtividade; as características do trabalho, tais como o transporte cargas de horário; o excesso de controle da gerência; a fragilização dos coletivos; as condições de trabalho inadequadas, que implicam em alimentação, sono e cuidados pessoais insuficientes; falta de lazer e descanso; esforço físico elevado para manutenção da produtividade; e o uso de inibidores do sono. Tais condições se agravam com o envelhecimento dos trabalhadores sem a contrapartida da alteração no ritmo, característica e condições de trabalho.

Verifica-se, em compensação, que todas essas condições são mais ou menos percebidas pelos trabalhadores que, sem condições adequadas de lhes fazer face, lançam mão de justificativas para adiar os cuidados necessários para enfrenta-las. Entre essas justificativas, o adoecimento e custos da atividade são parcialmente tolerados ou negados pelos trabalhadores, seja pela percepção dos benefícios e expectativas observadas na profissão, entre as quais perspectivas financeiras, identitárias e sociais, seja por meio de estratégias defensivas que sustentam a atividade calcadas em um "corpo-máquina" viril e que recusa a vergonha de portar um corpo frágil, seja pela valorização da lógica da eficácia, que é parcialmente introjetada por meio de uma pretensa "eterna disponibilidade" para o mercado por meio de um corpo continuamente disponível à ação, seja ainda pela desconsideração de dores e sofrimentos físicos e psíquicos que podem ser tolerados antes do agravamento das condições de saúde que acarretam no afastamento para o trabalho, seja, enfim, pela recusa da procura por um profissional médico que possui o poder de impor o afastamento independentemente dos desejos dos trabalhadores. O adoecimento só se torna possível quando o corpo para, impondo uma condição que não é fácil de se viver e o qual se protela o quanto pode, já que não se pode parar antes para evitar que esse momento chegue:

Cê" já não pode mesmo, "cê" já tá deficiente, não pode trabalhar mais, a gente quer trabalhar e não pode. "Cê" é proibido de fazer uma coisa que você quer fazer. A gente nasce naquele ritmo de trabalhar, trabalhar, quando você pára, ai meu Deus do Céu! É terrível, filha (E.4) 


\section{CONSIDERAÇÕES FINAIS}

Diante do exposto, compreende-se que o afastamento do trabalho dos motoristas de caminhão de rota longa configura-se de modo peculiar, a começar pelas expectativas mobilizadas para a escolha dessa profissão, que juntamente aos seus valores positivos - liberdade e prazer por dirigir e conhecer novos lugares - sustentam, em parte, a tolerância das situações de trabalho penosas por estes trabalhadores. Ficou evidente, a partir dos relatos colhidos, que algumas características e condições de trabalho identificadas inscrevem o afastamento do trabalho destes trabalhadores como decorrente de agravos à saúde, em geral, relacionados à atual organização do transporte rodoviário de cargas. Assim, dentre suas demandas, destaca-se as exigências no cumprimento dos prazos de entrega da carga, que determinam, em parte, as precárias condições de vida desses trabalhadores na estrada.

Outro aspecto característico desse afastamento é que em geral ocorre tardiamente, causado pelo adiamento ao máximo do cuidado, o que acarreta no agravamento das morbidades. Evidencia-se aí a influência dos modos de lidar com o adoecer neste processo, uma vez que tanto o aspecto financeiro como a tentativa de manutenção do corpo em atividade parecem ser causas deste adiamento. Em contrapartida, os dados revelaram que esses modos de lidar com o adoecer são influenciados pela marcante valorização da eficiência econômica neste contexto de trabalho, pelas concorrência no mercado de trabalho, pelas características do tipo de carga transportadas e pelas condições em que a profissão se exerce.

Estudos como este, reforçam a necessidade de integração das políticas de Saúde, Trabalho e Previdência Social bem como a revisão de práticas do INSS considerando-se que o atual modelo previdenciário mostra-se restrito a abordagens unilaterais não extensivas aos aspectos psicossociais do trabalhador. $\mathrm{Na}$ medida em que as práticas previdenciárias instituídas no país desconhecem ou ignoram os processos subjetivos produzidos pelos trabalhadores, elas acabam por contribuir para reforçar o agravamento das condições de saúde dos trabalhadores durante sua atividade laboral, quando estes, pelas razões acima demonstradas, adiam a busca de cuidado. Entre outros, para os caminhoneiros é o médico quem tem o poder de impor o afastamento do trabalho, independemente da vontade dos trabalhadores, e sem a intervenção nas condições que seu trabalho se desenrola. Práticas previdenciárias calcadas em outras perspectivas, considerando as dimensões socioambientais acima apontadas, poderiam ser elaboradas visando efeitos não apenas nos trabalhadores atendidos pelo INSS, mas também nas condições e características do trabalho, partilhadas por muitos trabalhadores.

Em outras palavras, esta pesquisa buscou contribuir para o conhecimento das percepções, sentimentos e saberes do motorista de caminhão de rota longa, 
aos quais revelam que sua incorporação na avaliação técnica do INSS poderá conduzir a uma maior acurácia no serviço de reabilitação profissional prestado pelo referido órgão.

\section{REFERÊNCIAS}

Antunes, R. (2015). Adeus ao Trabalho? Ensaio sobre as metamorfoses e a centralidade do mundo do trabalho (16 ed.). São Paulo, SP: Cortez Editora.

Bardin, L. (2015). Análise de conteúdo. São Paulo, SP: Edições 70.

Boltanski, L. (1979). As classes sociais e o corpo. Rio de Janeiro: Graal.

Botelho, L. J., Diesel, L. E., Adamczyk, J. F., \& Zeferino, M. T. (2011). Profissão motorista de caminhão: uma visão (im)parcial. Saúde e transformação social, 2(1), 108-113.

Bregalda, M. M., \& Lopes, R. E. (2011). O Programa de Reabilitação Profissional do INSS: apontamentos iniciais a partir de uma experiência. Cadernos de Terapia Ocupacional da UFSCar, 19(2), 249-262.

Campos, C. J. G. (2004). Método de análise de conteúdo: Ferramenta para a análise de dados qualitativos no campo da saúde. Revista Brasileira de Enfermagem, 57(5), 611-614. doi: 10.1590/S0034-71672004000500019

Canguilhem, G. (2011). O normal e o patológico (11 ed.). Rio de Janeiro, RJ: Forense Universitária.

Cerqueira, G. S., Siqueira, R. M. P., Fragoso, F. A. P., Leiros, W. d. S. B., Freitas, R. M., Sivla, R. C., \& Fragoso, L. d. M. (2011). Uso de anfetaminas entre caminhoneiros: Um estudo transversal. RevInter Revista Intertox de Toxicologia, Risco Ambiental e Sociedade, 4(2), 76-86. doi: 10.1590/S0034-89102007000200017

Clot, Y. (2010). Poder de agir. Belo Horizonte, MG: FabreFactum.

Dejours, C. (2012). Trabalho vivo (Vol. 1 e 2). Brasília, DF: Paralelo 15.

Dejours, C. (2015). A loucura do trabalho (5. ed.). São Paulo, SP: Cortez-Oboré. Falzon, P. (Ed.). (2007). Ergonomia. São Paulo, SP: Edgar Blucher

Fogaça, L. F., Santos, C. S., Souza, E. D., \& Morais, R. T. P. (2011). Identificação de caminhoneiros hipertensos da campanha de saúde na boleia de uma concessionária do interior de São Paulo. Nursing (São Paulo), 13(155), 204208.

Forzy, J.-F. (2007). Condução de automóveis e concepção ergonômica. In P. Falzon (Ed.), Ergonomia (pp. 557-571). São Paulo, SP: Blucher.

Franco, M. L. P. B. (2012). Análise de Conteúdo (4 ed. Vol. 6). Brasília, DF: Líber Livro.

Gaskell, G. (2008). Entrevistas individuais e grupais. In M. W. Bauer \& G. Gaskell (Eds.), Pesquisa qualitativa com texto, imagem e som: Um manual prático (pp. 64-89). Rio de Janeiro, RJ: Vozes. 
Hirata, H. (2002). Nova divisão sexual do trabalho? Um olhar voltado para a empresa e a sociedade. São Paulo, SP: Boitempo Editorial.

Januzzi, P. M. (2002). Mobilidade Social no Contexto de Adversidades Crescentes do Mercado de Trabalho Brasileiro dos Anos 1990. Economia e Sociedade, $11(2), 255-278$.

Kapron, R. A. (2012). História do trabalho dos caminhoneiros no Brasil: profissão, jornada e ações políticas. (Dissertação de Mestrado), Universidade Federal de Pelotas, Pelotas/RS.

Knauth, D. R., Pilecco, F. B., Leal, A. F., Seffner, F., \& Teixeira, A. M. F. B. (2012). Staying awake: Truck drivers' vulnerability in Rio Grande do Sul, Southern Brazil. Revista de Saúde Pública, 46(5), 886-893.

Maeno, M., \& Vilela, R. A. G. (2010). Reabilitação Profissional no Brasil: Elementos para a construção de uma política pública. Revista Brasileira de Saúde Ocupacional, 35(121), 87-99. doi: 10.1590/S030376572010000100010

Marqueze, E. C., Ulhôa, M. A., \& Moreno, C. R. C. (2012). Irregular working times and metabolic disorders among truck drivers: A review. Work, 41(0), 3718-3725. doi: 10.3233/WOR-2012-0085-3718

Molinié, A. F. (2002). Âge et Conditions de Travail dans I'Union Européenne. Dublin. Paris: Fondation européenne pour I'amélioration des conditions de vie et de travail.

Moraes, T. D., \& Athayde, M. (2014). Dimensões do coletivo na atividade de trabalho dos motoboys. Fractal, 26(2), 327-348. doi: 10.1590/19840292/906

Moraes, T. D., Rohr, R. V., \& Athayde, M. (2015). Ingresso, permanência e abandono na profissão de motoboys: Constituição de si e da profissão. Laboreal, 11(1), 69-83.

Nascimento, E. C., Nascimento, E., \& Silva, J. d. P. (2007). Uso de álcool e anfetaminas entre caminhoneiros de estrada. Revista de Saúde Pública, 41(2), 290-293. doi: 10.1590/S0034-89102007000200017

Nunes, I. (2011). Acumulação de capitais e sistemas de transportes terrestres no Brasil. In A. G. Filho \& P. R. C. Queiroz (Eds.), Transportes e formação regional contribuições à história dos transportes no Brasil (pp. 11-39). Dourados, MS: UFGD Editora.

Pope, C., \& Mays, N. (2009). Métodos qualitativos na pesquisa em saúde. In C. Pope \& N. Mays (Eds.), Pesquisa qualitativa na atenção à saúde (pp. 1119). Porto Alegre, RS: Artmed.

Ramos, S., \& Lacomblez, M. (2005). Envelhecimento, trabalho e cognição: 80 anos de investigação. Laboreal, 1(1), 52-60.

Rosa, I. (2006). Trilhando caminhos e perseguindo sonhos: histórias e memórias de caminhoneiros. (Dissertação de Mestrado), Universidade Federal de Uberlândia, Uberlândia. 
Ruiz, V. R., \& Araújo, A. L. L. (2012). Saúde e segurança e a subjetividade no trabalho: Os riscos psicossociais. Revista Brasileira de Saúde Ocupacional, 37(125), 170-180. doi: 10.1590/S0303-76572012000100020

Santos, G. S. H. (2015). O programa de reabilitação profissional do Instituto Nacional do Seguro Social e a reinserção do trabalhador no mercado de trabalho. (Dissertação de Mestrado), Universidade Federal de São Carlos, São Carlos.

Santos, M. M. (2007). Transporte rodoviário de cargas no Brasil: transportadores e sindicalismo a partir dos anos 1990. (Dissertação de Mestrado), Universidade Estadual de Campinas, Campinas.

Scaramella, M. L. (2004). Nessa longa estrada da vida: um estudo sobre as experiências dos caminhoneiros. (Dissertação de Mestrado), Universidade Estadual de Campinas, Campinas.

Seligmann-Silva, E. (2011). Trabalho e desgaste mental: O direito de ser dono de si mesmo. São Paulo, SP: Cortez.

Simonelli, A. P., Camarotto, J. A., Bravo, E. S., \& Vilela, R. A. G. (2010). Proposta de articulação entre abordagens metodológicas para melhoria do processo de reabilitação profissional. Revista Brasileira de Saúde Ocupacional, 35(121), 64-73. doi: 10.1590/S0303-76572010000100008

Souza, J. C., Paiva, T., \& Reimão, R. (2008). Sono, qualidade de vida e acidentes em caminhoneiros brasileiros e portugueses. Psicologia em Estudo, 13(3), 429-436. doi: 10.1590/S1413-73722008000300003

Takahashi, M. A. C., Kato, M., \& Leite, R. A. O. (2010). Incapacidade e reabilitação profissional e saúde do trabalhador: Velhas questões, novas abordagens. Revista Brasileira de Saúde Ocupacional, 35(121), 7-9. doi: 10.1590/S0303-76572010000100002

Trindade, Z., Menandro, M. C. S., \& Giarnórdoli-Nascimento, I. (2007). Organização e interpretação de entrevistas: Uma proposta de procedimento a partir da perspectiva fenomenológica. In M. M. P. Rodrigues \& P. R. M. Menandro (Eds.), Lógicas metodológicas: Trajetos de pesquisa em psicologia (pp. 71-92). Vitória, ES: GM Gráfica Editora.

Ulhoa, M. A., Marqueze, E. C., Lemos, L. C., Silva, L. G. d., Silva, A. A., Nehme, P., . . . Moreno, C. R. d. C. (2010). Distúrbios psíquicos menores e condições de trabalho em motoristas de caminhão. Revista de Saúde Pública, 44(6), 1130-1136. doi: 10.1590/S0034-89102010000600019

Veronese, A. M. (2004). Moto-boys de Porto Alegre: Convivendo com os riscos de acidentes. (Dissertação de Mestrado), Universidade Federal do Rio Grande do Sul, Porto Alegre.

Vogel, L. (2001). La dimensión de género en salud laboral-Primeras conclusiones de una encuesta europea La dimensión de género en salud laboral: Primeras conclusiones de una encuesta europea. Retrieved from www.etuc.org/tutb/fr/femmes 
Sobre os autores

Lívia Guimarães Delfino é terapeuta ocupacional pela Faculdades Integradas São Pedro, mestre em psicologia pela Universidade Federal do Espírito Santo. Trabalha no serviço de reabilitação profissional do Instituto Nacional de Seguridade Social do Espírito Santo. livia.gdelfino@gmail.com Thiago Drumond Moraes é psicólogo pela Universidade Federal do Espírito Santo, doutor em psicologia social pela Universidade do Estado do Rio de Janeiro. Trabalha na linha de psicologia do trabalho e das organizações e recebe financiamento de pesquisa da FAPES. thiago.moraes@ufes.br

Recebido em: 26/11/2015

Revisado em: 24/01/2016 Aceito em: 29/01/2016 